\title{
Temporary duodenal stenting as a bridge to ERCP for inaccessible papilla due to duodenal obstruction: a retrospective study
}

Authors

Institutions
Gianfranco Donatelli ${ }^{1}$, Fabrizio Cereatti ${ }^{2}$, Jean-Loup Dumont ${ }^{1}$, Parag Dhumane ${ }^{3}$, Thierry Tuszynski ${ }^{1}$, Serge Derhy ${ }^{4}$, Alexandre Meduri ${ }^{1}$, Bertrand Marie Vergeau' ${ }^{1}$, Bruno Meduri

${ }^{1}$ Unité d’Endoscopie Interventionnelle, Ramsay Générale de Santé, Hôpital Privé des Peupliers, Paris, France

2 Unit of Interventional Endoscopy, Department of General Surgery “P. Stefanini”, “Sapienza” University of Rome, Rome, Italy

${ }^{3}$ Department of General and Laparoscopic Surgery, Lilavati Hospital and Research Center, Bandra(w), Mumbai, India

${ }^{4}$ Unité de Radiologie Interventionnelle, Ramsay Générale de Santé, Hôpital Privé des Peupliers, Paris, France submitted 5. February 2016 accepted after revision 18. April 2016

\section{Bibliography}

Dol http://dx.doi.org/ 10.1055/s-0042-107070 Published online: 12.5.2016 Endoscopy International Open 2016; 04: E957-E963

(c) Georg Thieme Verlag KG Stuttgart . New York E-ISSN 2196-9736

\section{Corresponding author} Gianfranco Donatelli Unité d'Endoscopie Interventionnelle Ramsay Générale de Santé, Hôpital Privé des Peupliers 8 Place de l' Abbé G. Hénocque 75013, Paris

France

Phone: +33664950070

Fax: + 330144165615

donatelligianfranco@gmail.com
Background and study aims: Duodenal obstruction may prevent performance of endoscopic retrograde cholangiopancreatography (ERCP). Percutaneous transhepatic biliary drainage (PTBD) or Endoscopic ultrasonograhy-guided biliary access (EUS-BD) are alternative treatments but are associated with a higher morbidity and mortality rate. The aim of the study is to report overall technical success rate and clinical outcome with deployment of temporary fully or partially covered self-expanding duodenal stent (pc/ fcSEMS) as a bridge to ERCP in case of inaccessible papilla due to duodenal strictures.

Patients and methods: This retrospective study included 66 consecutive patients presenting with a duodenal stricture impeding the ability to perform an ERCP. Provisional duodenal stenting was performed as a bridge to ERCP. A second endoscopic session was performed to remove the provisional stent and to perform an ERCP. Afterward, a permanent duodenal stent was delivered if necessary.

\section{Introduction \\ $\nabla$}

Inability to reach the papilla due to duodenal obstruction related to neoplastic invasion, by extrinsic compression or as a consequence of benign pathologies, may preclude ERCP performance. Percutaneous transhepatic cholangiography or EUS-guided biliary access are mini-invasive alternative treatments associated with a morbidity up to $31 \%$ and $17 \%$, respectively [1].

Provisional insertion of removable covered selfexpanding metal stents (CSEMS) has been introduced in the last decade with the goal of dilating benign strictures in the gastrointestinal tract caused by pyloric $[2,3]$ or esophageal peptic stenosis, gastrointestinal anastomosis [4, 5], and radiation-induced stenosis. CSEMS have been used as well in the treatment of gastrointestinal leaks [6]. Moreover, the use of temporary duodenal
Results: Sixty-six duodenal stents (17 pcSEMS and 49 fcSEMS) were delivered with a median indwelling time of $3.15(1-7)$ days. Two migrations occurred in the pcSEMS group, 1 of which required lower endoscopy for retrieval. No other procedure-related complications were observed. At second endoscopy a successful ERCP was performed in 56 patients (85\%); 10 patients (15\%) with endoscopic failure underwent PTBD or EUSBD. Forty patients needed permanent duodenal stenting.

Conclusions: Provisional removable covered duodenal stenting as a bridge to ERCP for duodenal obstruction is safe procedure and in most cases allows successful performance of therapeutic ERCP. This technique could be a sound option as a step up approach before referring such cases for more complex techniques such as EUS-BD or PTBD.

stents has been described in literature for management of perforated duodenal ulcer or perivaterian perforation after ERCP $[7,8]$.

Provisional deployment of SEMS to overcome duodenal strictures may be a therapeutic option to allow an ERCP procedure after a few days. SEMS removal, usually after 7 days, does not represent a problem and, in most cases, allows an ERCP to be performed, as shown in anecdotal reports [9].

The aim of this retrospective study is to report overall technical success rates, clinical outcomes, and rates of adverse events associated with deployment of temporary fully or partially covered duodenal stents (fcSEMS/pcSEMS) as a bridge to ERCP in cases of inaccessible papilla due to duodenal strictures in a single tertiary endoscopic center. 


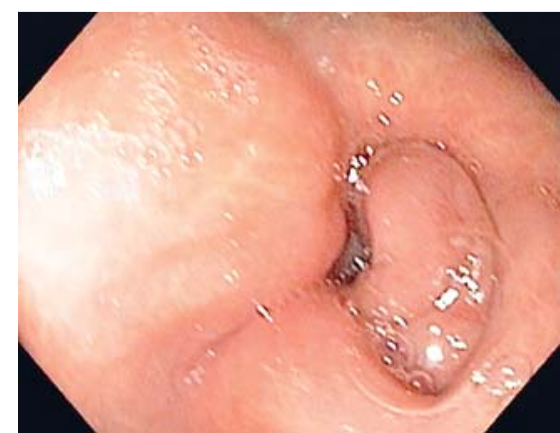

Fig. 1 Endoscopic view of pyloric and duodenal stricture due to exstrinsic compression.

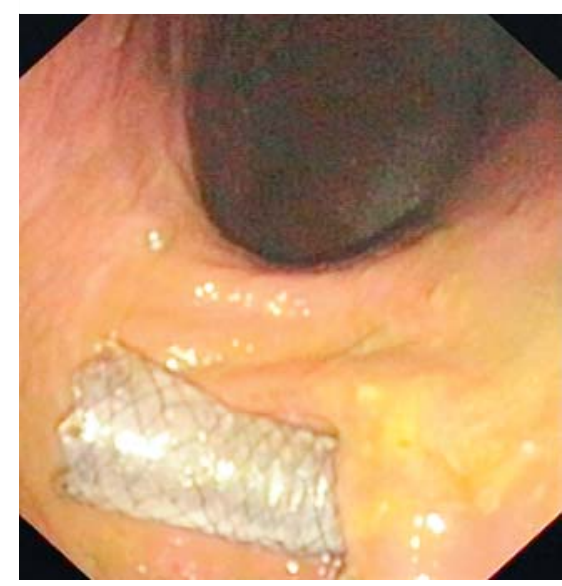

Fig. 2 Endoscopic view after provisional duodenal stent deployment for duodenal stricture due to extrinsic compression.

\section{Patients and methods}

Between January 2010 and November 2015, a total of 9000 ERCPs were performed by our team at our private institution. Sixty-six patients (26 male, 40 female) with an average age of 73 years ( $S D \pm 13.7$ ) in whom ERCP could not be performed due to inability to reach the papilla underwent duodenal CSEMS deployment as a bridge to ERCP. Included were all consecutive patients with a duodenal stricture impeding performance of ERCP and no prior history of biliary endoscopic interventions. Ten patients in whom the same approach was successful were excluded due to previously performed biliary procedures. This exclusion criterion was adopted to evaluate the efficacy of our technique only in cases of naïve papillae.

Data were collected in a prospectively maintained database and retrospectively reviewed and analyzed. Technical and clinical outcome plus complication rates for temporary duodenal stenting and subsequent stent removal and ERCP performance were recorded. Comparison of the results according to stricture etiology and location and type of duodenal stent used was performed to search for potential predictors of success with our approach. Informed consent, including need for multiple endoscopic sessions, was obtained from all patients. The study was approved by the Institutional Review Board for Human Research.

Duodenal stricture was present in all patients. In 54 patients ( $82 \%)$ there was no notion of duodenal stricture before index endoscopy. Meanwhile 12 patients (18\%) presented with nausea and vomiting on hospital admission. Considering Mutignani et al's "bilioduodenal stricture" classification [10], stricture location was at the level of the duodenal bulb or upper duodenal genu in 49 patients and affecting the second part of the duodenum with papilla involvement in the remaining 17 patients.

\section{Procedure}

All procedures were performed under general anesthesia; prophylactic antibiotics were administered in all cases and continued until the first endoscopic control in the 11 patients with cholangitis.

Duodenal stricture was defined as inability to reach the papilla of Vater due to duodenal neoplastic invasion or extrinsic compression ( Fig.1) even after balloon dilation up to $20 \mathrm{~mm}$. Before considering provisional duodenal stenting, a large balloon traction technique was attempted as described by Kikuyama et al. [11]

In 16 patients the examination was started with an array echoendoscope (GFUE140, GFUE180, Olympus ${ }^{\circledR}$ linear, Japan) and stopped at the pylorus or bulb because of stenosis. However, in 10 of 16 patients FNA-EUS was successfully performed from the bulb or stomach for 6 pancreatic masses, 2 lymph nodes and 2 bile duct lesions. In all other patients a standard duodenoscope (TJF160 VR, TJF180 V, Olympus ${ }^{\circledR}$, Japan) was used. After reaching the stenosis, through-the-scope contrast injection was always performed to evaluate the length and degree of the stenosis. Several attempts to overcome the stricture were done with change of the patient's position (supine and left lateral side) and, if no neoplasia was present, performance of hydrostatic dilation up to $20 \mathrm{~mm}$. Balloon dilation was not performed in case of tumoral invasion of the duodenal wall due to the high risk of perforation related to such a procedure.

In case of failure even after balloon dilation, the subject was enrolled in the study and a Tandem ${ }^{\circledR}$ catheter (Boston Scientific ${ }^{\circledR}$, Massachusetts, USA) was used to insert a $450-\mathrm{cm}$ guide wire in the distal duodenum. Afterward a partially or fully covered Self Expandable Metal Stent (pcSEMS or fcSEMS) (Hanarostent, M.I. Tech, Seoul, South Korea-TaeWoong Medical, Co., Ltd, Gimpo-si, South Korea) was inserted ( $\bullet$ Fig. 2). All SEMS were $20 \mathrm{~mm}$ in diameter whereas stent length $(9,10,11$ or $13 \mathrm{~cm})$ and the use of pcSEMS or fcSEMS were at the discretion of the endoscopist. As a general rule the proximal end of the stent was delivered across the pylorus while the location of the distal end was related to stricture length irrespective of papilla location. We were not concerned about the stent covering the papillary region because the mesh in the stent prevented watertight closure of the papilla. PCSEMS was generally preferred in cases of short or low-grade stricture as an attempt to reduce the risk of migration.

Patient demographics and pathology characteristics are listed in - Table 1. Patients were allowed an oral diet on the day of the procedure. Repeat endoscopy was performed between at a minimum of 2 and a maximum of 7 days. The time span for each patient was determined based on the individual's clinical condition and degree of tightness so as to maximize stent expansion across the narrowing and to reduce the risk of migration and ingrowth or overgrowth of inflammatory tissue ( $\bullet$ Fig. 3a,b).

During the second endoscopic session a plain abdominal x-ray was always performed to evaluate the degree of expansion of the stent. Afterward duodenoscopy across the stent was attempted and if it was not possible, hydrostatic intra-stent dilation up to $20 \mathrm{~mm}$ was performed using a $\mathrm{CRE}^{\circledR}$ balloon (Boston Scientific ${ }^{\circledR}$, Massachusetts, USA). Thereafter stent removal was easily carried out using a foreign body forceps. Only after successful stent removal was an endoscopic retrograde cholangiopancreatography (ERCP) attempted. Permanent duodenal stenting was performed, if clinically necessary, at the end of the ERCP, delivering an uncovered duodenal SEMS. 
Table 1 Patient demographics and pathologic features.

\begin{tabular}{|l|c|}
\hline Age & $\mathbf{7 3}(\mathbf{\pm 1 3 . 7}$ SD) \\
\hline Sex & 26 male, 40 female \\
\hline Clinical presentation(\%) & \\
\hline Jaundice & $51(77 \%)$ \\
\hline Pain & $3(4.5 \%)$ \\
\hline Cholangitis & $11(17 \%)$ \\
\hline Biliary leak & $1(1.5 \%)$ \\
\hline Diagnosis (\%) & \\
\hline Pancreatic cancer & $40(60.6 \%)$ \\
\hline CBD stones & $7(10.6 \%)$ \\
\hline Chronic pancreatitis & $5(7.6)$ \\
\hline CBD cancer & $6(9 \%)$ \\
\hline Duodenal cancer & $1(1.5 \%)$ \\
\hline Diffuse metastatic lesion & $7(10.6 \%)$ \\
\hline Characteristic of duodenal stenosis (\%) & $15(23 \%)$ \\
\hline Tumoral invasion & $5(7 \%)$ \\
\hline Peptic stenosis & $46(70 \%)$ \\
\hline Extrinsic compression
\end{tabular}

\section{Outcome parameters}

Technical success was defined as the ability to deploy the pc/ fCSEMS across the duodenal stenosis.

Complete expansion of the pc/fcSEMS was defined as complete resolution of the waist at the level of stenosis. Bleeding, perforation, pancreatitis, dysphagia, and stent migration were evaluated and considered as procedural/technical complications related to SEMS deployment/retrieval. Clinical success was defined as the capability to perform a successful therapeutic ERCP following dilation of the duodenum with pc/fc SEMS with decrease of jaundice or resolution of cholangitis. Complications related to subsequent ERCP and duodenal permanent stenting were evaluated and considered as follow: bleeding, pancreatitis, perforation, cholangitis, cholecystitis, dysphagia, and vomiting due to stent malfunctioning. Mean follow up was 45 (7-90) days. Because most patients had end-stage disease, longer follow up was not feasible.

\section{Statistical analysis}

Frequency, percentages, means $( \pm S D)$, and medians were used for descriptive analysis.

Categorical variables were compared using the Chi-squared test (or Fischer's exact test when necessary). Freeman Halton extension of Fischer test was used as well when necessary.

A two tailed $P$ value $<0.05$ was considered statistically significant.
Statistical analysis were performed using IBM SPSS Statistics 20 (IBM Company, Arnock, New York, USA).

\section{Results}

Indications for ERCP were as follow: jaundice in 51 patients, cholangitis in 11 cases, chronic pancreatitis-related pain in 3 patients, and biliary leak following cholecystectomy in 1 subject. Underlying pathologies responsible for biliary symptoms were: 40 pancreatic cancer, 6 bile duct cancer, 1 duodenal cancer, 5 chronic pancreatitis, 7 common bile duct (CBD) stones, and 7 diffuse metastatic disease from different cancers (2 breast, 1 gastric, 1 ovarian, 1 kidney and 1 colon).

Technical success was achieved in all 66 patients (100\%). Sixtysix stents were delivered for the following pathologies: neoplastic duodenal invasion in 15 patients, peptic stenosis in 5, and extrinsic compression in 46. The extrinsic compression group comprised 7 patients with no evidence of malignant disease ( 5 chronic pancreatitis and 2 undetermined non-malignant compression) and 39 patients with EUS-evident tumoral compression on the duodenal wall. Seventeen of $66(25.8 \%)$ patients had a pcSEMS and $49(74.2 \%)$ patients had a fcSEMS. The length of pcSEMS was $9 \mathrm{~cm}$ in 13 cases and $11 \mathrm{~cm}$ in 4 , with the length of deployed fcSEMS as follow: $10 \mathrm{~cm}$ in 32 cases, $11 \mathrm{~cm}$ in 9 , and $13 \mathrm{~cm}$ in the remaining 8 .

There was no bleeding, pancreatitis, dysphagia or perforation following stent deployment. At an average of 3.15 days $(1-7)$ follow up, endoscopy showed 53 stents fully expanded, 2 migrations, and 11 stents that were incompletely expanded. In the latter 11 patients, a hydrostatic dilation up to $20 \mathrm{~mm}$ was carried out. A $3 \%$ migration rate was observed. Both migrations occurred in the pcSEMS arm. Stent length was 13 and $10 \mathrm{~cm}$, respectively, while original pathology was pancreatic cancer in the first patient and chronic pancreatitis in the second, which in both cases caused extrinsic compression. Migration was diagnosed 3 days after SEMS deployment even if no stricture resolution was noted. One patient expelled the stent spontaneously per ano while the other patient underwent colonoscopy for retrieval. The outcomes of the study are summarized in 0 Fig. 4.

Statistical analysis showed a numeric but not statistically significant difference between $\mathrm{pc}$ and fcSEMS groups $(P=0.0634)$ concerning the migration rate.

No statistically significant differences in terms of the migration rate were highlighted in the study when considering stricture characteristics (neoplastic invasion vs peptic stricture vs extrinsic
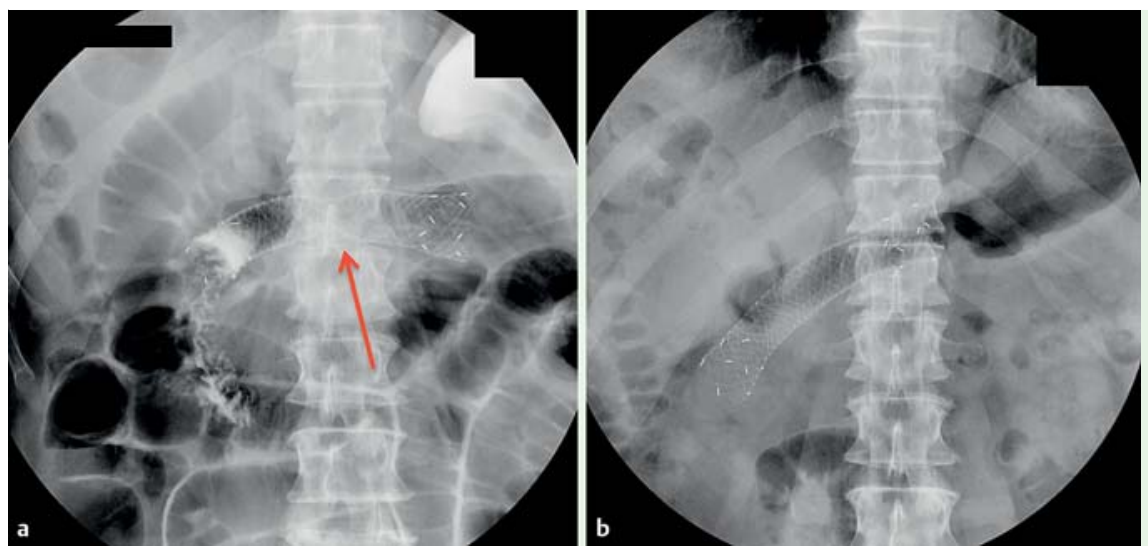

Fig.3 a Radiological view after stent deployment across duodenal stricture. $\mathbf{b}$ Radiological view before stent removal showing full expansion and a slight migration of the stent. 


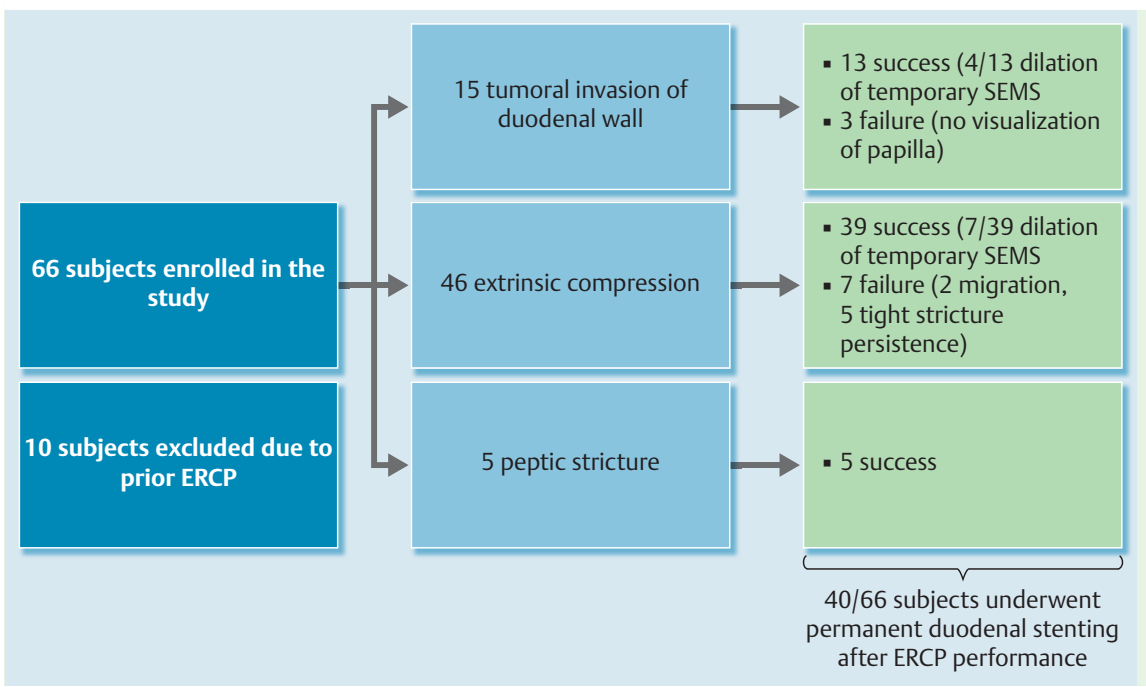

Fig.4 Outcomes summary.

compression) with a $P$ value $=0.638$. Nor were days of stenting significant ( $\leq 3$ days $v s>3$ days) with a $P$ value $=0.509$.

All stents were removed without complication after 1 day in 9 patients, 2 days in 10, 3 days in 18 subjects, 4 days in 22, 5 days in 2 patients, and after 7 days in the remaining 3 subjects. Subsequent duodenoscopy and successful therapeutic ERCP could be performed in 56 out 66 patients (85\%) with delivery of biliary plastic or metal stent, stone removal in 1 patient, and pancreatic prosthesis in 2 patients. ERCP failed in 10 patients (15\%). Reasons for failure included: inability to recognize the papilla due to neoplastic invasion in 3 patients, persistence of tight duodenal narrowing in 5 cases, and early stent migration and stricture persistence in the remaining 2 cases. Stricture location failures occurred in 2 patients with a duodenal bulb stricture and in 8 patients with a stricture involving the papillary region. The characteristics of the failed procedures are described in $\bullet$ Table 2.

Eight out of 10 patients underwent same-day percutaneous biliary drainage by means of transhepatic cholangiography (PTBD) and 2 underwent transduodenal EUS biliary drainage (EUS-BD) with a choledocoduodenal anastomosis during the same session ( $\bullet$ Fig.5a-d). One of the 2 EUS biliary drainage patients presented 24 hours later with a biliary leak and consequent peritonitis and underwent emergency surgery with a double gastric and biliary bypass. Two of 8 PTBD patients had major postprocedural bleeding requiring blood transfusions.

Following biliary drainage, permanent duodenal stenting with insertion of an uncovered duodenal stent (Wallflex ${ }^{\circledR}$, Boston Scientific, Massachusetts, USA) was performed in 40 out 66 patients due to tight duodenal stricture and clinically evident GOO. After 5 days 1 patient with chronic pancreatitis underwent biliary and gastric by-pass. Neither bleeding nor perforations were reported after ERCP procedures. Two patients developed moderate postERCP pancreatitis, according to the Cotton et al. classification [12] and both cases resolved with medical treatment. There was no procedure related-mortality. At a mean follow-up of 45 days (7-90), liver enzymes and bilirubin levels improved in all 66 patients; moreover no patient required revision of the duodenal stent or biliary re-stenting.

Differences in failure rate among the different groups were compared to search for statistically significant risk factors that influenced clinical outcome. However, no statistically significant differences were found comparing pcSEMS vs fcSEMS $(P$ value $=$ 0.717 ) and considering the different types of stenosis: neoplastic invasion vs peptic stricture vs extrinsic compression $(P=0.737)$ (๑ Table 3 and $\bullet$ Table 4 ).

Table 2 Clinical features of failed procedures.

\begin{tabular}{|c|c|c|c|c|c|c|c|c|}
\hline Sex & Age & Pathology & Type of stenosis & $\begin{array}{l}\text { Type of } \\
\text { Stent }\end{array}$ & $\begin{array}{l}\text { Indwel- } \\
\text { ling time } \\
\text { (days) }\end{array}$ & Cause of failure & $\begin{array}{l}\text { Alternative bili- } \\
\text { ary drainage }\end{array}$ & $\begin{array}{l}\text { Permanent } \\
\text { duodenal } \\
\text { stenting }\end{array}$ \\
\hline M & 69 & Diffuse metastasis & extrinsic compression & $10 \mathrm{~cm} \mathrm{FC}$ & 7 & Tight duodenal stricture & PTBD & YES \\
\hline M & 95 & pancreas malignancy & extrinsic compression & $10 \mathrm{~cm} \mathrm{FC}$ & 2 & Tight duodenal stricture & $\begin{array}{l}\text { Duodenal EUS-BD } \\
\text { (billie leak } \rightarrow \text { Surg) }\end{array}$ & NO \\
\hline $\mathrm{F}$ & 87 & pancreas malignancy & extrinsic compression & $10 \mathrm{~cm} \mathrm{FC}$ & 2 & Tight duodenal stricture & Duodenal EUS-BD & NO \\
\hline $\mathrm{F}$ & 85 & pancreas malignancy & extrinsic compression & $10 \mathrm{~cm} \mathrm{FC}$ & 4 & Tight duodenal stricture & PTBD & NO \\
\hline M & 63 & pancreas malignancy & extrinsic compression & $13 \mathrm{~cm} \mathrm{FC}$ & 4 & Tight duodenal stricture & PTBD & YES \\
\hline M & 69 & pancreas malignancy & extrinsic compression & $13 \mathrm{~cm} \mathrm{FC}$ & 3 & Migration (stenosis) & PTBD & YES \\
\hline $\mathrm{F}$ & 67 & pancreas malignancy & neoplastic invasion & $10 \mathrm{~cm} \mathrm{FC}$ & 4 & No papilla visualization & $\begin{array}{l}\text { PTBD } \\
\text { (Bleeding) }\end{array}$ & YES \\
\hline M & 73 & pancreas malignancy & neoplastic invasion & $9 \mathrm{~cm} \mathrm{PC}$ & 4 & No papilla visualization & PTBD & NO \\
\hline M & 55 & Chronic pancreatitis & extrinsic compression & $10 \mathrm{~cm} \mathrm{FC}$ & 3 & Migration (stenosis) & PTBD & Surgery \\
\hline $\mathrm{F}$ & 68 & K pancreas & neoplastic invasion & $9 \mathrm{~cm} \mathrm{PC}$ & 3 & No papilla visualization & $\begin{array}{l}\text { PTBD } \\
\text { (Bleeding) }\end{array}$ & Yes \\
\hline
\end{tabular}

M, male; F, female; PTBD, percutaneous transhepatic biliary drainage 


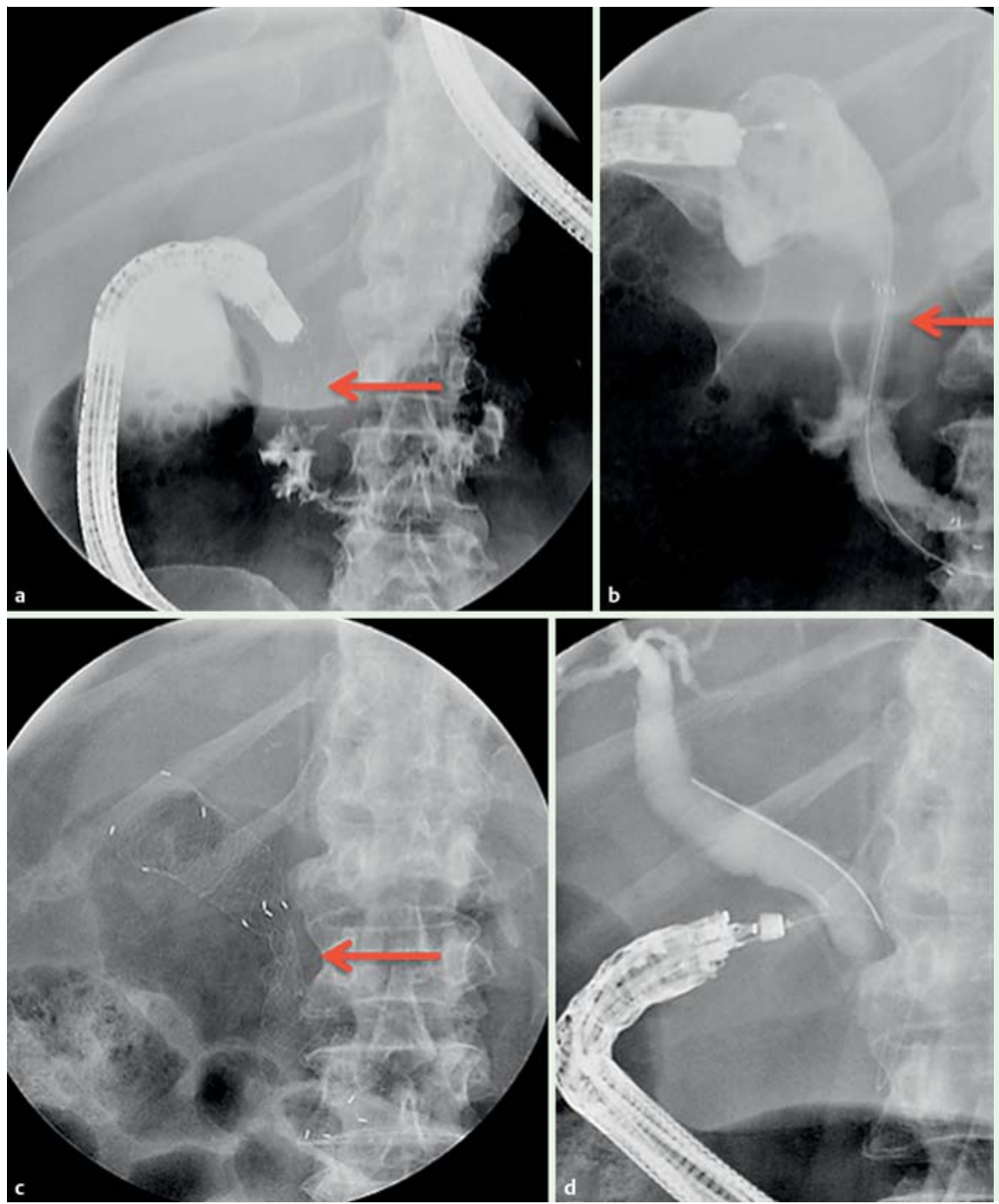

Fig. 5 a Contrast opacification of a stricture of the second portion of the duodenum. $\mathbf{b}$ Stent deployment with severe waist. $\mathbf{c}$ Incomplete expansion of stent 2 days later. $\mathbf{d}$ EUS Cholangiography successfully performed after stent removal showing a neoplastic stricture of the intrapancreatic choledochus.

Table 3 Comparison of migration rate, stent type, stricture nature and indwelling time.

\begin{tabular}{|c|c|c|c|c|}
\hline & $\begin{array}{l}\text { Total } \\
\text { number }\end{array}$ & $\begin{array}{l}\text { Migra- } \\
\text { tion }\end{array}$ & $\begin{array}{l}\text { Migration } \\
\text { rate }\end{array}$ & $P$ value \\
\hline \multicolumn{5}{|l|}{ Stent type } \\
\hline FC-SEMS & 49 & 0 & $0 \%$ & \multirow[t]{3}{*}{$P=0.0634$} \\
\hline PC-SEMS & 17 & 2 & $11,70 \%$ & \\
\hline Total SEMS & 66 & 2 & $3 \%$ & \\
\hline \multicolumn{5}{|l|}{ Stricture nature } \\
\hline Neoplastic invasion & 15 & 0 & $0 \%$ & \multirow[t]{4}{*}{$P=0.639$} \\
\hline Peptic disease & 5 & 0 & $0 \%$ & \\
\hline $\begin{array}{l}\text { Extrinsic abdominal } \\
\text { compression }\end{array}$ & 46 & 2 & $4,30 \%$ & \\
\hline Total patients & 66 & 2 & $3 \%$ & \\
\hline \multicolumn{5}{|l|}{ Indwelling time } \\
\hline$\leq 3$ days & 39 & 2 & $5,10 \%$ & \multirow[t]{3}{*}{$P=0.509$} \\
\hline$>3$ days & 27 & 0 & $0 \%$ & \\
\hline Total SEMS & 66 & 2 & $3 \%$ & \\
\hline
\end{tabular}

Fc-SEMS, fully covered self-expanding metal stent; Pc-SEMS, partially covered self-expanding metal stent; SEMS, self-expanding metal stent
Table 4 Comparison of failure rate, stent type, and stricture nature.

\begin{tabular}{|c|c|c|c|c|}
\hline & $\begin{array}{l}\text { Total } \\
\text { number }\end{array}$ & Failure & $\begin{array}{l}\text { Failure } \\
\text { rate }\end{array}$ & $P$ value \\
\hline \multicolumn{5}{|l|}{ Stent type } \\
\hline Fc-SEMS & 49 & 8 & $16 \%$ & \multirow[t]{3}{*}{$P=0.717$} \\
\hline PC-SEMS & 17 & 2 & $11.80 \%$ & \\
\hline Total SEMS & 66 & 10 & $15 \%$ & \\
\hline \multicolumn{5}{|l|}{ Stricture nature } \\
\hline Neoplastic invasion & 15 & 3 & $20 \%$ & \multirow[t]{4}{*}{$P=0.737$} \\
\hline Peptic disease & 5 & 0 & $0 \%$ & \\
\hline $\begin{array}{l}\text { Extrinsic abdominal } \\
\text { compression }\end{array}$ & 46 & 7 & $15.20 \%$ & \\
\hline Total patients & 66 & 10 & $15 \%$ & \\
\hline
\end{tabular}

Fc-SEMS, fully covered self-expanding metal stent; Pc-SEMS, partially covered self-expanding metal stent; SEMS, self-expanding metal stent 


\section{Discussion}

$\nabla$

Biliary endoscopic sphincterotomy (BES) has been accepted as the gold standard treatment for choledocholithiasis and malignant biliary-pancreatic pathologies [13]. However the "condition sine qua non" is to pass through the duodenum and recognize the papilla. Duodenal obstruction is a condition that can be present both in malignant pathologies such as biliopancreatic or duodenal cancer or diffuse metastatic pathologies and in benign ones such as peptic ulcer, benign pylorus stenosis or chronic pancreatitis.

In case of nonresectable pathology and concomitant gastric outlet obstruction, a recent systematic review [14] showed the superiority of permanent duodenal stenting compared to palliative surgical approaches.

Covered duodenal stents are already used for the management of fistula and leak, gastrointestinal anastomotic strictures, radiation-induced stenosis, and benign pyloric stenosis. However, covered stents are burdened by a high migration rate due to the presence of the cover that minimizes hyperplastic tissue ingrowth through the mesh [15].

In our study we propose expanding the indication for temporary duodenal stenting as a bridge to ERCP for refractory duodenal strictures.

However, our ERCP success rate after temporary duodenal stenting is still lower than the $90 \%$ success rate suggested as a reasonable minimal standard [16]. These data may be explained by the peculiar settings in which the "second attempt ERCP" was carried out. First, even if our technique allowed us to dilate the stricture and reach the papilla, the duodenum, due to underlying pathology, was sub-stenotic and rigid in most cases. Approach to the papillary region was cumbersome and ability to manipulate the duodenoscope and accessories was often limited. Second, in two-thirds of the failed ERCPs (3 out of 10), it was possible to overcome the stenosis but impossible to visualize the papilla. In such circumstances, an EUS and endoscopic rendezvous approach with anterograde introduction of a guidewire across the papilla could be attempted [17].

In the 10 cases in which "second-attempt ERCP" was unsuccessful, 8 patients underwent PTBD instead of EUS-BD. PTBD was preferred in 3 subjects due to neoplastic invasion of the duodenum preventing creation of a choledochoduodenostomy and in 1 patient with chronic pancreatitis because in our Institution, we currently prefer to perform PTBD for benign pathologies. Meanwhile, in the remaining 4 patients, the decision to undergo to PTBD vs EUS-BD was defined by the referring surgeon.

According to our results, long and severe stricture, papillary region involvement, and tumoral invasion of the duodenal wall are potential predictors of failure and must be carefully considered before attempting our technique. Moreover all aforementioned features are typical of neoplastic etiology and are often present simultaneously. Indeed, in our series, 9 of 10 patients in which the procedure failed had disease with a malignant etiology.

Despite a tertiary referral center for interventional biliopancreatic endoscopy, we adopt a step-up approach before more invasive treatments such as EUS-BD PTBD as both are associated with high rates of morbidity and mortality $[18,19]$.

Percutaneous transhepatic biliary drainage is the gold standard second-line treatment after failure of ERCP or in case of altered anatomy that precludes ERCP performance. Since the first PTBD, major advances have led to biliary drainage becoming a well-es- tablished procedure worldwide [20]. Nowadays PTBD and subsequent stenting achieve an extremely high clinical success rate hindered, however, by a high morbidity rate [21].

In our experience, in the near future, EUS-BD is likely to become a fundamental tool for the biliopancreatic endoscopist; however, before that happens, EUS-BD techniques must be standardized and new dedicated devices developed.

Regarding standardization of the technique in the literature, there are few studies reporting EUS-BD in patients with concomitant obstructive jaundice and duodenal obstruction $[22,23]$ and even fewer comparing the 2 different EUS-BD approaches available: hepaticogastrostomy (HGS) versus choledocoduodenostomy (CDS). Moreover, reported outcomes are discordant. In their retrospective study of 39 patients, Ogura et al. [24], reported a longer stent patency and a lower AE rate for HGS. Meanwhile Dhir et al. in turn reported a statistically significant higher complication rate for the transhepatic route compared to that in a multicenter retrospective study on the transduodenal one [25]. In a large comparative study, Poincloux et al [26], reported no differences between CDS and HGS in terms of technical success, clinical outcome, and complication rate. As reported by many experts, further prospective randomized controlled clinical trials are needed to validate the efficacy and safety of EUS-BD.

Several studies in the literature $[10,27]$ describe different approaches to manage malignant "bilioduodenal stricture". Mutignani et [10] al reported their experience in 64 patients with "bilioduodenal strictures" undergoing ERCP through a duodenal stent. The study showed good results with an acceptable rate of complications. However, in our opinion, such an approach is appropriate only in a tertiary referral hospital. Performance of an ERCP through the mesh of a duodenal stent is often cumbersome, demanding a high level of expertise and very often requiring technically demanding procedures such as balloon dilation of the mesh or stent trimming by means of foreign body forceps or APC. Our technique, in constrast, requires only temporary duodenal stenting which is feasible even in less experienced centers.

As aforementioned, Kikuyama et al's [11] large balloon traction technique is a very useful tool for overcoming several but not all duodenal strictures. Such an interesting technique can be attempted, whenever feasible, before considering provisional stenting.

In the current study we excluded 10 patients in whom a biliary stent (plastic or metallic) was endoscopically positioned before development of a duodenal stricture. Nonetheless we adapted our technique even for those 10 patients, successfully removing and exchanging both plastic and metallic stents and avoiding a cumbersome EUS or radiological procedure for stent replacement.

We reported a lower stent migration rate compared to that reported in the current literature [28]. Our low migration rate may be explained by the short indwelling time of the stents (average 3.15 days), the degree and nature of the stricture treated, and some technical tricks. Stent were left in place for such a short time because our aim was just to dilate the stricture and allow the passage of the duodenoscope. Moreover, it typically takes up to 48 hours for a stent to achieve complete expansion so it is necessary to maintain it for that period to achieve maximal radial force. We always deploy at least half of the stent above the stenosis in order to allow a certain degree of physiologic migration and, as a general rule, we always try to release the proximal end of the stent across the pylorus. Moreover it is important to avoid 
stent impaction at the horizontal portion of the duodenum in order to avoid occlusion.

In our experience, the factor key to minimizing the rate of migration is keeping the stent as short as possible, just enough to achieve its full expansion. Unexpectedly the 2 migrations occurred in the pcSEMS group. That may be due to the fact that pcSEMS were preferred in cases of slack or short strictures.

Similar to other authors [29,30], we did not experience complications related to mechanical occlusion of the papilla due to duodenal SEMS. That may be explained by the fact that covering the papillary region does not induce watertight closure. Stent removal after a maximum of 7 days was always feasible.

Temporary covered duodenal stenting as a bridge to ERCP for duodenal obstruction is safe and in $85 \%$ of cases, allowed us to successfully perform therapeutic ERCP. Temporary duodenal stenting may be a sound option as a step-up approach before referring such patients for more complex techniques such as EUS$\mathrm{BD}$ or PTBD. Such a technique could be very useful as a first-line approach, even in smaller endoscopic centers that do not have the expertise or the availability of an endosonographer or interventional radiologist. Long and complete obstruction due to tumor infiltration of the second part of the duodenum, however, remains a factor predictive of failure requiring alternative biliary drainage techniques.

Competing interests: Dr. Donatelli is a consultant for Boston Scientific.

\section{References}

1 Khan MA, Akbar A, Baron TH et al. Endoscopic Ultrasound-Guided Biliary Drainage: A Systematic Review and Meta-Analysis. Dig Dis Sci 2016; 61: 684-703

2 Heo J, Jung MK. Safety and efficacy of a partially covered self-expandable metal stent in benign pyloric obstruction. World J Gastroenterol 2014; 20: $16721-16725$

3 Choi WJ, Park JJ, Park J et al. Effects of the temporary placement of a self-expandable metallic stent in benign pyloric stenosis. Gut Liver 2013; 7: 417-422

4 Sharaiha RZ, Kim KJ, Singh VK et al. Endoscopic stenting for benign upper gastrointestinal strictures and leaks. Surg Endosc 2014; 28: $178-$ 184

5 Cereatti F, Fiocca F, Dumont JL et al. Fully covered self expandable metal stent in the treatment of post-surgical colorectal disease: outcome in 29 patients. Ther Adv Gastroenterol. DOI 10.1177/1756283X15610052

6 Donatelli G, Dhumane P, Perretta $S$ et al. Endoscopic placement of fully covered self expanding metal stents for management of post-operative foregut leaks. J Minim Access Surg 2012; 8: 118 -124

7 Bergström M, Arroyo Vázquez JA et al. Self-expandable metal stents as a new treatment option for perforated duodenal ulcer. Endoscopy 2013; 45: $222-225$

8 Lee SM, Cho KB. Value of temporary stents for the management of perivaterian perforation during endoscopic retrograde cholangiopancreatography. World J Clin Cases 2014; 16: 689-697

9 Poincloux L, Goutorbe F, Rouquette $O$ et al. Biliary stenting is not a prerequisite to endoscopic placement of duodenal covered self-expandable metal stents. Surg Endosc 2016; 30: 437-445

10 Mutignani M, Tringali A, Shah SG et al. Combined endoscopic stent insertion in malignant biliary and duodenal obstruction. Endoscopy 2007; 39: 440-447
11 Kikuyama M, Itoi T, Sasada Yet al. Large-balloon technique for one-step endoscopic biliary stenting in patients with an inaccessible major papilla owing to difficult duodenal stricture (with video). Gastrointest Endosc 2009; 70: 568-572

12 Cotton PB, Lehman G, Vennes J et al. Endoscopic sphincterotomy complications and their management: an attempt at consensus. Gastrointest Endosc 1991; 37: 383-393

13 Vaira D, D'Anna L, Ainley C et al. Endoscopic sphincterotomy in 1000 consecutive patients. Lancet 1989; 2: 431-434

14 Nagaraja V, Eslick GD, Cox MR. Endoscopic stenting versus operative gastrojejunostomy for malignant gastric outlet obstruction - a systematic review and meta-analysis of randomized and non randomized clinical trial. J Gastrointest Oncol 2014; 5: 92 -98

15 Waidmann O, Trojan J, Friedrich-Rust M et al. SEMS vs cSEMS in duodenal and small bowel obstruction: high risk of migration in the covered stent group. World J Gastroenterol 2013; 19: 6199-6206

16 Baron T, Petersen BT, Mergener Ket al. Quality indicators for Endoscopic Retrograde Cholangiopancreatography. Gastrointest Endosc 2006; 63: 29-S34

17 Dhir V, Kwek B, Bhandari $S$ et al. EUS guided biliary rendezvous using a short hydrophilic guidewire. J Interv Gastroenterol 2011; 4: 153-159

18 Vila J, Perez-Miranda M, Vazquez-Sequeiros E et al. Initial experience with EUS-guided cholangiopancreatography for biliary and pancreatic duct drainage: a Spanish national survey. Gastrointest Endosc 2012; 76: $1133-1141$

19 Winick A, Waybill P, Venbrux A. Complications of percutaneous transhepatic biliary interventions. Tech Vasc Interv Radiol 2001; 4: 200206

20 Molnar W, Stockum AE. Relief of obstructive jaundice through percutaneous transhepatic catheter: a new therapeutic method. Am J Roentgenol Radium Ther Nucl Med 1974; 122: 356-367

21 Uberoi R, Robertson I. The British Society of Interventional Radiology first Biliary Drainage and Stent audit report. ISBN 1-903968-24-0

22 Iwamuro M, Kawamoto $H$, Harada $R$ et al. Combined duodenal stent placement and endoscopic ultrasonography-guided biliary drainage for malignant duodenal obstruction with biliary stricture. Dig Endosc 2012; 22: 236-240

23 Belletrutti PJ, DiMaio CJ, Gerdes $H$ et al. Endoscopic ultrasound guided biliary drainage in patients with unapproachable ampullae due to malignant duodenal obstruction. J Gastrointest Cancer 2011; 42: 137 142

24 Ogura T, Chiba Y, Masuda D et al. Comparison of the clinical impact of endoscopic choledochoduodenostomy and hepaticogastrotomy for bile duct obstruction with duodenal obstruction. Endoscopy. DOI 10.1055/s-0034-1392859

25 Dhir V, Artifon EL, Gupta K et al. Multicenter study on endoscopic ultrasound-guided expandable metal stent placement: choice of access route, direction of stent insertion and drainage route. Dig Endosc 2014; 26: 430-435

26 Poincloux L, Rouquette O, Buc E et al. Endoscopic ultrasound-guided biliary drainage after failed ERCP: cumulative experience of 101 procedures at a single center. Endoscopy 2015; 47: 794-801

27 Moon JH, Choi HJ, Ko BM et al. Combined endoscopic stent-in-stent placement for malignant biliary and duodenal obstruction by using a new duodenal stent (with videos). Gastrointest Endosc 2009; 70: $772-776$

28 Lee H, Min BH, Lee JH et al. Covered metallic stents with an anti-migration design vs. uncovered stents for the palliation of malignant gastric outlet obstruction: a multicenter, randomized trial. Am J Gastroenterol 2015; 110: 1440-1449

29 Song $H Y$, Shin JH, Yoon CJ et al. A dual expandable nitinol stent: experience in 102 patients with malignant gastroduodenal strictures. J Vasc Interv Radiol 2004; 15: 1443 - 1449

30 Yoon CJ, Song HY, Shin JH et al. Malignant duodenal obstructions: palliative treatment using self-expandable nitinol stents. J Vasc Interv Radiol 2006; 17: 319-326 